\title{
Exploring the assumptions of multi-stock assessment models for humpback whales (Megaptera novaeangliae) in the Southern Hemisphere: using Breeding Stocks $D$ and $E$ as an example
}

\author{
Rebecca Leaper*\#, SAmantha Peel* ${ }^{*}$, David PeEL ${ }^{+}$And Nick Gales* \\ Contacte-mail: rebecca.leaper@utas.edu.au
}

\begin{abstract}
There is potential value in exploring multi-stock models to address situations where humpback stocks are mixing. However, sensitivity to the assumptions underlying these models has yet to be fully explored. Using a simple simulation approach, the assumptions of a population model that allows for mixing of humpback whale (Megaptera novaeangliae) stocks D and E on feeding areas has been explored by relaxing the assumptions of the original Johnston and Butterworth model in a number of plausible ways. First the ability of the model to estimate parameters was checked for a situation where simulated data are generated from an underlying model of exactly the same form for which the actual values of these parameters are known (Scenario 1). Then the ability of the model to estimate these parameters when alternative forms and assumptions were used for the underlying model generating the data was investigated. Specifically, stocks were allowed to mix non-uniformly across each feeding area and catch was non-uniformly distributed across each feeding area (Scenario 2). The consequences of density dependence implemented on feeding rather than breeding areas (Scenario 3) were also examined. The original mixing model was robust to alternate mixing and catch allocation scenarios in all but one of the simulations, but when density dependence acted at the level of the feeding rather than the breeding areas, the model produced estimates that were quite different from the underlying population. It is recommend that the inclusion of density dependence on feeding areas in models that allow for mixing of whales on these grounds be investigated further.
\end{abstract}

KEYWORDS: HUMPBACK WHALE; ASSESSMENT; MIXING; CATCH ALLOCATION; DENSITY DEPENDENCE; SIMULATION; MODELLING

\section{INTRODUCTION}

The IWC Scientific Committee (SC) has been involved in the Comprehensive Assessment (CA) of Southern Hemisphere humpback whales (Megaptera novaeangliae) each year since 2000 (IWC, 2001). To date, assessments have been based on an age-aggregated production model (IWC, 1998) using either maximum likelihood estimation (e.g. Findlay et al., 2000), or more recently Bayesian estimation (e.g. Zerbini, 2005). In addition, assessments have been based on breeding rather than feeding stocks (IWC, 1998), of which there are currently seven putative stocks termed A to G (IWC, 2005; fig. 1 of IWC, 2011, p.3) and have proceeded on the basis of alternative plausible scenarios of catch allocations to these breeding areas (e.g. Johnston and Butterworth, 2004).

In an effort to complete the CA of Southern Hemisphere humpback whales, an intersessional meeting was held in 2006 to review and update the historical catch record, as well as reviewing stock structure information and stock specific abundance and trend estimates. An important task was to consider how this new information could be used to parameterise the age-aggregated production model currently used for the assessment of each breeding stock and whether this model would require modification with respect to the following issues: (1) the allocation of feeding area catches to breeding stocks, notably when mixing of two or more breeding stocks on a feeding area is suspected; (2) the treatment of abundance estimates from the feeding areas when allocation of animals to breeding areas is uncertain;
(3) the treatment of possible substructure in the breeding areas; and (4) the incorporation of demographic parameters not typically included in modelling (e.g. depensation).

The review revealed that the knowledge and level of confidence associated with humpback whale stock structure concepts varies considerably across the Southern Hemisphere. In some areas (e.g. Breeding Stock A and Area II), the connections between breeding and feeding areas and the structure within these is reasonably well understood. Here a single breeding stock is connected with a single feeding area. In others (e.g. Breeding Stocks B, C, E and F), there is considerable unresolved complexity and insufficient data to discriminate among a variety of stock structure hypotheses. At one extreme there is substantial substructure within breeding areas (i.e. stocks B and C) and there is also mixing of stocks on feeding areas but probably little exchange between breeding areas (i.e. stocks D and E); at the other extreme there is both substructure within a breeding stock, and mixing of stocks on both feeding and breeding areas (i.e. stocks E and F). Under any one of these stock structure scenarios, it is virtually impossible to provide reliable data (e.g. absolute abundance estimates, abundance trends and historical catch) for assessment models, and model runs based on alternative plausible scenarios for input data have, as yet proved unsatisfactory (IWC, 2011). The issue of how the assessment can best be completed, given such complex stock structure therefore remains an outstanding task.

One possible approach to this problem is to adopt a framework that allows for some degree of stock complexity

\footnotetext{
* Australian Marine Mammal Centre, Australian Antarctic Division, Department of Sustainability, Environment, Water, Population and Communities, 203 Channel Highway, Kingston 7050, Tasmania, Australia.

* Institute of Marine and Antarctic Studies, University of Tasmania, Private Bag 49, Hobart, TAS 7001, Australia.

CSIRO Mathematical and Information Sciences, GPO Box 1538, Hobart, Tasmania 7001, Australia.
} 
in the model itself. In the North Atlantic, where humpback whales feed in discrete aggregations but mix on breeding areas, multi-stock models have already been used for assessment (Friday et al., 2001). For Southern Hemisphere humpback whales, a similar multi-stock approach has been used to assess stocks D and E (West and East Australia) (Johnston and Butterworth, 2002; Johnston and Butterworth, 2005a; Johnston and Butterworth, 2005b), but these models have not yet been fully explored under the CA. In part this reflects the ongoing debate as to the extent to which stocks $\mathrm{D}$ and $\mathrm{E}$ mix on their feeding areas. Thus further exploration of multi-stock models and the underlying assumptions of such models may at the very least inform further model development, and at most, hopefully advance the assessment of populations with more complex stock structures. As a first step towards this goal, the assumptions underlying the model framework used by Johnston and Butterworth (2002) to assess Breeding Stocks D and E, are explored in this paper using a simple simulation approach. The sensitivity of the Johnston and Butterworth (2002) mixing model to its assumptions is explored when these are relaxed in a number of plausible ways, and in particular explore the consequences of alternate mixing, catch allocation and density dependence scenarios. The aim is not to present an assessment of Breeding Stocks D and E, but simply to use these stocks as a case study to explore the consequences of these alternative assumptions.

\section{The Johnston and Butterworth mixing model and its underlying assumptions}

The multi-stock model developed by Johnston and Butterworth (2002) is an extension of the basic ageaggregated production model (IWC, 1998) used in the single stock case. It allows two breeding stocks to mix on feeding areas such that catches taken in the feeding areas are apportioned to each breeding stock relative to the numbers present in that feeding area. The model makes a number of assumptions: (1) mixing of two breeding stocks occurs uniformly within two feeding areas; (2) historic catch is distributed uniformly within these two feeding areas; and (3) density dependence impacts whales on the breeding areas. Data from Breeding Stocks D and E were used as inputs to the model, having been updated for subsequent model runs (Johnston and Butterworth, 2005a; 2005b).

Humpback whales that breed close to the west (stock D) and the east coast (stock E) of Australia are thought to restrict their feeding to IWC Management Areas IV $\left(70^{\circ} \mathrm{E}-130^{\circ} \mathrm{E}\right)$ and $\mathrm{V}\left(130^{\circ} \mathrm{E}-170^{\circ} \mathrm{W}\right)$ respectively (Fig. 1). However, evidence from a variety of sources suggests that the stocks mix in these feeding areas. Analysis of catch returns taken in areas IV and V throughout the 1950s, supplemented by recoveries of Discovery marks, suggests an exchange of whales across both feeding areas, especially a movement of whales from Breeding Stock $E$ to the feeding areas east of $115^{\circ} \mathrm{E}$ in Area IV (Chittleborough, 1959; 1965; Dawbin, 1966). More recently, genetic data have lent support this idea, given an instance of a mark-recapture biopsy first sampled in the western part of Area $\mathrm{V}$ subsequently resampled in the eastern part of Area IV (IWC, 2002). Clues to the historic distribution of humpback whales in Areas IV and $\mathrm{V}$ come from the recently updated IWC catch data series (Allison, 2006). It is clear from these data (Figs 1a-c) that the catch for Areas IV and V is not uniformly distributed across these management areas. Sightings data from both the IDCR/SOWER circumpolar cruises and JARPA sightings surveys also suggest that whales are currently encountered
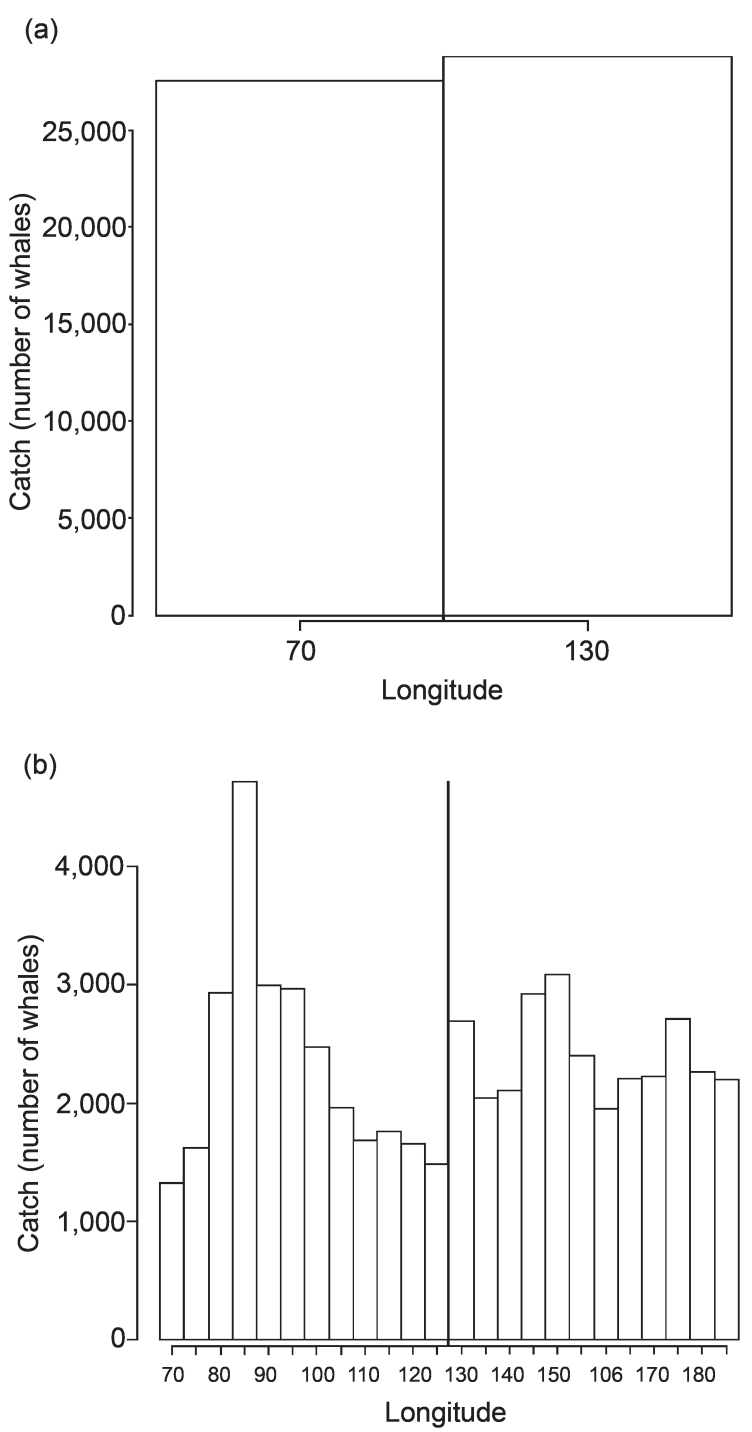

(c)

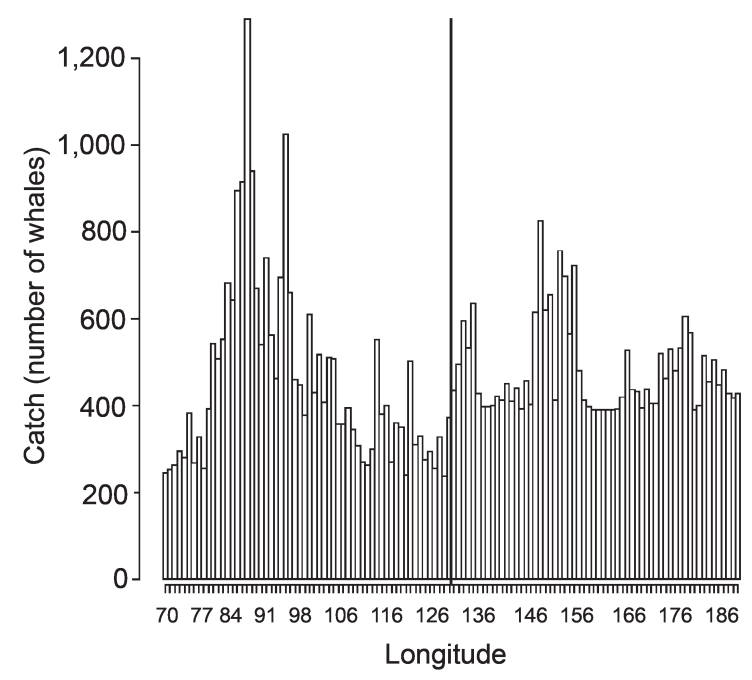

Fig. 1. The distribution of historic catch south of $40^{\circ} \mathrm{S}$ by longitude across IWC management areas IV and V, for (a) 2 sub-areas (b) 24 sub-areas and (c) 120 sub-areas.

more frequently at $20^{\circ}-40^{\circ} \mathrm{E}, 80^{\circ} \mathrm{E}-100^{\circ} \mathrm{E}, 150^{\circ} \mathrm{E}-180 \mathrm{E}^{\circ}$ and $40^{\circ} \mathrm{W}-70^{\circ} \mathrm{W}$ (IWC, 2006).

Alternative specifications for density dependence (e.g. on feeding areas rather than breeding areas) are especially 
important to consider in cases of models that allow stocks to mix. Under a scenario where only a single stock is being considered (or a scenario when there is no mixing between two stocks), then feeding area density dependence will be equivalent to breeding area density dependence. Furthermore, if the mixing across feeding areas is constrained to be fixed over time then feeding area density dependence will again be no different to breeding area density dependence. However, when the proportions of a stock that move are not fixed through time, breeding area density dependence and feeding area density dependence will not be equivalent. This can be demonstrated by a simplified example. When two stocks (that mix) are both at carrying capacity on a feeding area (i.e. zero net growth) and a large catch is taken from the feeding area of one of the stocks, then under the assumption of feeding area density dependence, both stocks will show an increase the following year. Conversely, when breeding area density dependence is assumed, then only the stock that has a large catch will show an increase as the other stock will still be at carrying capacity. Implementing feeding area density dependence is problematic as it is intrinsically tied to the underlying process of mixing on the feeding area; in the absence of empirical data on whale foraging and movement there may be several plausible hypotheses for the process of mixing. For example, there is evidence to suggest site philopatry on feeding areas for humpback whales where calves learn their feeding ground by accompanying their mothers (IWC, 2002); here mixing is a function of individual whale behaviour. Conversely, whales may have a random probability of feeding in particular areas and hence mixing may be a function of any one of a whole suite of mechanisms related to resource availability and/or foraging strategies.

\section{Objectives \\ Scenario 1}

In order to test sensitivity of estimates from the Johnston and Butterworth (2002) mixing model to alternate mixing, catch allocation and density dependence, a 'base case model' was developed that matched the original model assumptions (Scenario 1). Input data for the Johnston and Butterworth (2002) mixing model were generated using known selected values for the underlying parameters; these values were then compared with estimates obtained by fitting the model to the data generated (Fig. 2). The ability of the model to estimate these parameters from real input data (where the parameter values are unknown) can also then be measured. If comparisons between the simulated 'true population' and that estimated by the Johnston and Butterworth (2002) model outputs are good, it seems that the base case scenario provides a robust benchmark with which to assess alternate scenarios. Because this is a first step towards investigating model assumptions, a full scale simulation approach (i.e. add noise to the input data) was not adopted. Rather, the aim was simply to investigate how well the (Johnston and Butterworth, 2002) mixing model performed, if in 'reality' the population behaved in a more complex way on the feeding areas. Therefore the assessment of alternate scenarios is qualitative only. On this basis a further two different scenarios were examined.

\section{Scenario 2}

The original assumption of uniform mixing of two breeding stocks in two feeding (IWC management) areas is relaxed so that stocks now mix non-uniformly across each feeding area. This is implemented by simply: (a) increasing the number of feeding (sub-) areas from 2 to a further 6, 12, 24, 60 or 120 sub-areas across the two (IWC) management areas; and (b) specifying a mixing proportion for each sub-area based on one of two theoretical distributions, defined here as either gamma or highend (see Figs 3a and 4b). The catch is allowed to be distributed non-uniformly across these six sub-areas, again with one of two mixing distributions, either gamma or highend. The combined effect of non-uniform mixing and non-uniform catch produces quite different underlying catch allocations amongst the breeding stocks than Scenario 1 or the Johnston and Butterworth (2002) model.

\section{Scenario 3}

In contrast to the Johnston and Butterworth (2002) model, density dependence acts at the level of the feeding areas. Stock mixing and catch allocation are as defined for the original (i.e. base case) model, where mixing and catch are uniformly distributed across two sub-areas.

\section{DATA AND METHODS}

\section{Catch data}

Stocks D and E were assumed to feed exclusively in both Antarctic feeding areas IV $\left(70^{\circ} \mathrm{E}-130^{\circ} \mathrm{E}\right)$ and V $\left(130^{\circ} \mathrm{E}-\right.$ $\left.170^{\circ} \mathrm{W}\right)$, with no humpback whales from other breeding areas feeding in these management Areas. However, the IWC allocation of catch for these stocks (Naïve hypothesis) (IWC, 1998, p. 181 ) corresponds to $60^{\circ} \mathrm{E}-120^{\circ} \mathrm{E}$ (most of Area IV) and $120^{\circ} \mathrm{E}-170^{\circ} \mathrm{W}$ (most of Area V). For each scenario examined, exactly the same catch data as detailed in Johnston and Butterworth (2006) was used, where an ad hoc adjustment was made to these catches to make allowance for the extra 10 degrees of the latter set of catches which should correspond to the Area IV catch (see Appendix 1).

Only $\sim 75 \%$ of catches in the IWC dataset were however, resolved to the level of individual whale catch location ('individual data'), the remainder being summarised at a much coarser spatial scale ('summary data'). Hence, for the scenario where the two feeding areas were divided into further sub-areas, 'summary data' catches were allocated evenly across the all sub-areas.

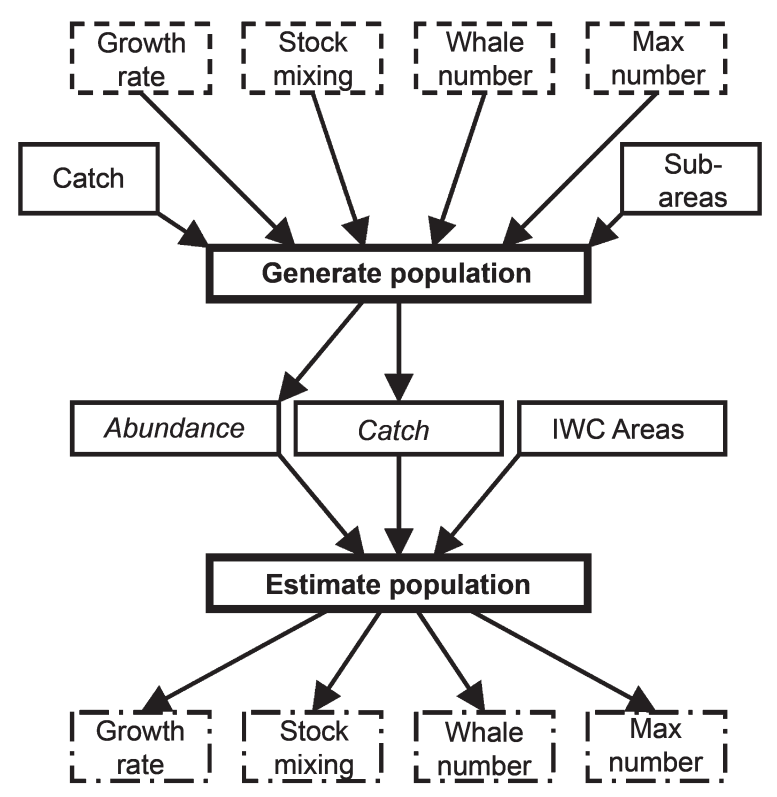

Fig. 2. A schematic of the model simulation process used for the base case and two test scenarios. Values in the dashed boxes are selected by the user and the values in the dot-dashed boxes are model estimates. 

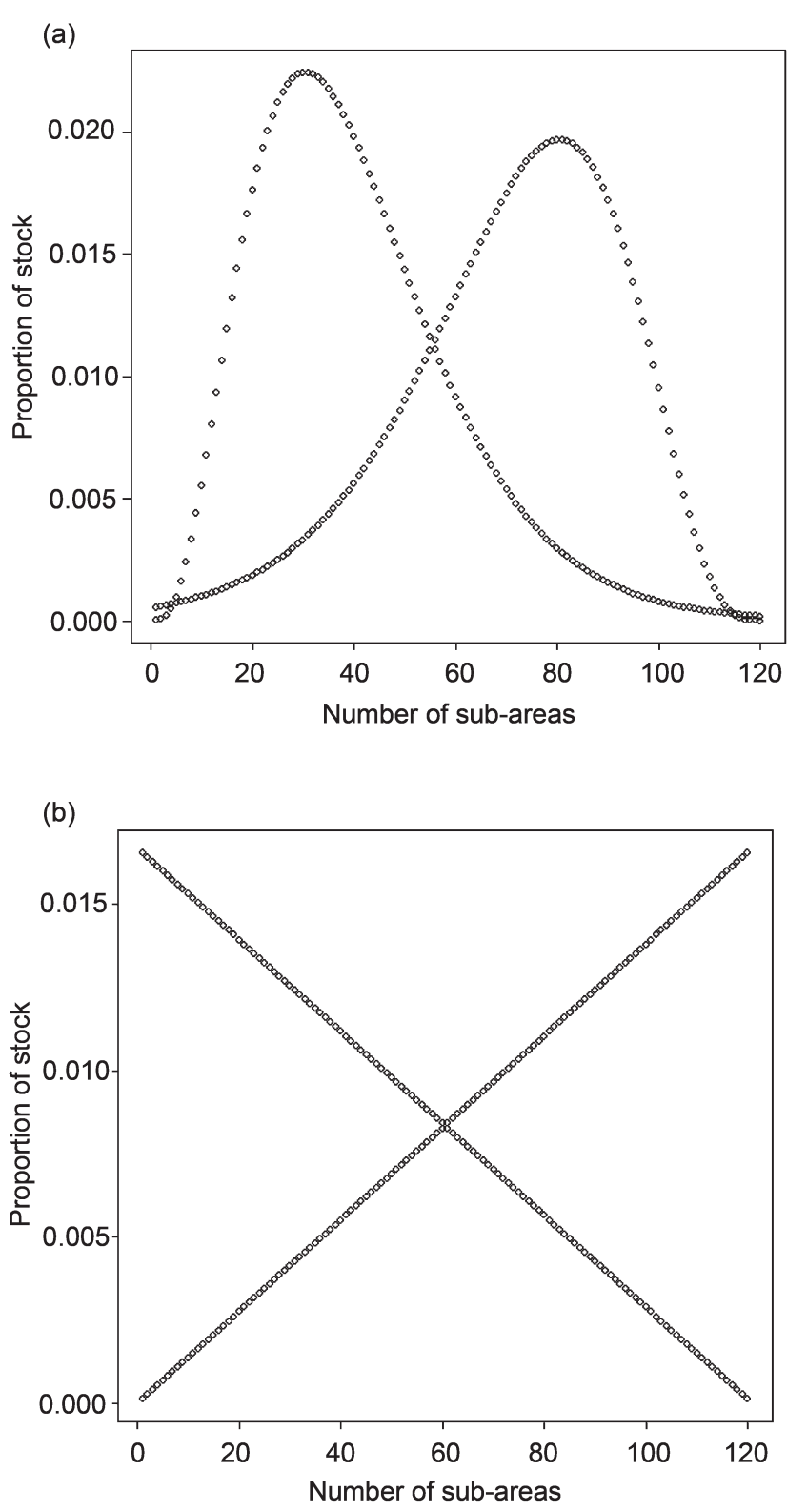

Fig. 3. Spatial distribution of mixing of both stocks in the feeding areas (i.e. proportion of stock in each sub-area) based on (a) gamma distribution and (b) highend distribution.

\section{Population dynamics models}

The Johnston and Butterworth (2002) population dynamics model allows for mixing of breeding populations in feeding areas, it takes as input data:

(1) historical catch data for the breeding and feeding areas;

(2) relative abundance estimates for the breeding and feeding areas; and

(3) absolute abundance estimates for the breeding grounds.

The stock growth rates, pre-exploitation abundance (carrying capacity) and proportions (the parameters alpha $(\alpha)$ and beta $(\beta)$ that drive the mixing across feeding areas) were most recently estimated within a Bayesian framework (Johnston and Butterworth, 2005a; 2005b). For the purposes of this paper the most recent model formulation and fitting procedure, i.e. Johnston and Butterworth (2005a) was used. The likelihood function is given by equation 13 in Johnston and Butterworth (2005a). Data were generated for the years 1900 to 2051 .
General mixing model

The population dynamics equation for the general mixing model, a generalisation of the mixing model described in Johnston and Butterworth (2005a), is:

$$
N_{y+1, s}=N_{y, s}+r_{s} N_{y, s}\left(1-\left(\frac{N_{y, s}}{K_{s}}\right)^{\mu}\right)-C_{y, s}
$$

where:

$N_{y, s}$ is the abundance of breeding stock $s$ in year $y$;

$r_{s}$ is the intrinsic growth rate of stock $s$;

$K_{S}$ is the carrying capacity of stock $s$;

$\mu$ is the 'degree of compensation' parameter (conventionally assumed to be 2.39 by the IWC/SC); and

$C_{y, s}$ is the number of stock $s$ caught in year $y$.

In this model, the common feeding ground of the breeding stocks is divided into equal areas. Note that for practical purposes, the value of should be chosen so that these areas evenly overlay the existing IWC management areas. For example, for stocks D and $\mathrm{E}$ that are assumed to feed jointly in management areas IV and $\mathrm{V}, n$ is even so that areas $1, \ldots, \frac{n}{2}$ are equivalent to management area IV and areas $\frac{n}{2}+1, \ldots, n$ are equivalent to management area $\mathrm{V}$. If the common feeding ground was to be divided into only the management areas IV and $\mathrm{V}$, then use $n=2$ (as in Johnston and Butterworth, 2005a).

The mixing of the breeding stocks $(s=1, \ldots, S)$ in a common feeding ground is described by:

$$
N_{y, A}=\sum_{s \in S} p_{s, A}^{N} N_{y, s}
$$

where:

$N_{y, A}$ is the number of whales in feeding area $A$ in year $y$; and $p_{s, A}^{N}$ is the proportion of stock that feeds in feeding area $A$. The overall catch from each breeding stock is:

$$
C_{y, s}=C_{y, s}^{B}+\sum_{A=1}^{n} C_{y, s, A}^{F}
$$

where:

$C_{y, s}$ is the number of stock $s$ caught in year $y$;

$C_{y, s}^{B}$ is the number of stock $s$ caught in the breeding ground in year $y$; and

$C_{y, s, A}^{F}$ is the number of stock $s$ caught in feeding area $A$ in year $y$.

Using the assumption in Johnston and Butterworth (2005a) that catches of stocks in a feeding area are in the same ratio as the numbers of each stock present there, the numbers of each stock caught in a feeding area can be calculated from:

$$
\frac{C_{y, s, A}^{F}}{C_{y, A}^{F}}=\frac{p_{s, A}^{N} N_{y, s}}{N_{y, A}}
$$

where:

$C_{y, A}^{F}$ is the number of whales caught in feeding area $\mathrm{A}$ in year $y$, i.e. $\sum_{s \in S} C_{y, s, A}^{F}$. 


\section{Base case model}

The base case model comprises the general mixing model with two breeding stocks (i.e. $=\{D, E\}$ ) and two feeding areas within the common feeding ground (i.e. $n=2)$ ). These feeding areas are equivalent to the two management areas IV and V. Eighty per cent of breeding stock D is set to feed in management area IV and $80 \%$ of breeding stock $\mathrm{E}$ is set to feed in management area $\mathrm{V}$, for all years. Thus, the mixing proportion of the breeding stock within the feeding ground is:

$$
p_{s, A}^{N}=\left[\begin{array}{ll}
0.8 & 0.2 \\
0.2 & 0.8
\end{array}\right]
$$

\section{Non uniform mixing and catch allocation model}

The non-uniform mixing and catch allocation model uses the general mixing model with two breeding stocks (i.e. $S=$ $\{D, E\})$ and a number of feeding areas within the common feeding ground (see Table 1 and Appendix 2). The mixing of the stocks within the feeding ground is distributed nonuniformly using separate functions for each stock. That is:

$$
N_{y, A}=\sum_{s \in S} f_{s}(y, A)
$$

where $f_{s}$ is as specified in Table 1. The catch of each stock within the feeding ground is determined using the available spatial catch information on an annual scale.

\section{Feeding area density dependence model}

The population dynamics equation for the feeding area density dependence model is:

$$
\begin{aligned}
N_{y+1, s, A} & =N_{y, s, A}+r_{s} N_{y, s, A}\left(1-\left(\frac{N_{y, A}}{K_{A}}\right)^{\mu}\right)-C_{y, s, A} \\
N_{y+1, s} & =\sum_{A=1}^{n} N_{y+1, s, A}
\end{aligned}
$$

where:

$N_{y, s, A}$ is the abundance of stock $\mathrm{s}$ in feeding area in $A$ in year $y$

$r_{s}$ is the intrinsic growth rate of stock $s$;

$K_{A}$ is the carrying capacity of feeding area $A$; $\mu$ is the 'degree of compensation' parameter (conventionally assumed to be 2.39 by the IWC/SC); and

$C_{y, s, A}$ is the number of stock $s$ in feeding area in $A$ caught in year $y$.

The initial numbers of each breeding stock that feeds in each feeding area in year 0 is calculated as:

$$
N_{0, s, A}=p_{s, A}^{N} N_{0, s}
$$

where $p^{N}$ and $N_{0, s}$ are as described for the base case mixing model. In this scenario $p^{N}$ refers to the initial state at year zero only, as the subsequent yearly mixing proportions are allowed to change.

The catch from each stock in each feeding area is

$$
C_{y, s, A}=C_{y, s, A}^{B}+C_{y, s, A}^{F}
$$

where:

$C_{y, S}^{B}$ is the number of stock $s$ that feed in feeding area $A$ caught in the breeding ground in year $y$; and

$C_{y, s, A}^{F}$ is the number of stock $s$ caught in feeding area $A$ in year $y$.

$C_{\nu s, A}^{B}$ is unknown but can be estimated in the same manner as $C_{y, S, A}^{F}$ in the general mixing model, i.e.

$$
C_{y, s, A}^{B}=C_{y, s}^{B} \frac{N_{y, s, A}}{N_{y, s}}
$$

where:

$C_{y, s}^{B}$ is the number of stock $s$ caught in the breeding ground in year $y$; and

$N_{y, s}$ is the number of stock $s$ in year $y$.

\section{Model performance under the different scenarios}

For each of three different scenarios, the performance of the 'True' simulated population with that estimated by the (Johnston and Butterworth, 2005a) model, 'Estimated' by reporting the normalised mean square error (NMSE) was qualitatively assessed between the two population trajectories across all years.

\begin{tabular}{|c|c|c|c|}
\hline Parameters & Scenario 1 & Scenario 2 & Scenario 3 \\
\hline Number of areas & Management Areas IV and V & $\begin{array}{l}2,6,12,24,60 \text { and } 120 \mathrm{sub} \text { areas within } \\
\text { the common feeding area }\end{array}$ & Management Areas IV and V \\
\hline Catch - feeding area $\left(\mathrm{S} 40^{\circ} \mathrm{S}\right)$ & Appendix 1 & $\begin{array}{l}\text { Appendix } 1 \text { with spatial information } \\
\text { where available }\end{array}$ & Appendix 1 \\
\hline Catch - breeding area $\left(\mathrm{N} 40^{\circ} \mathrm{S}\right)$ & Naïve & Naïve & Naïve \\
\hline Stock mixing strategy & $\begin{array}{l}\text { Uniformly distributed across } \\
\text { Management areas IV and V }\end{array}$ & $\begin{array}{l}\text { Distributed using a: (1) gamma function, } \\
\text { one for each stock; and ( } 2 \text { ) high-end } \\
\text { function, one for each stock }\end{array}$ & $\begin{array}{l}\text { Uniformly distributed within } \\
\text { Management areas IV and V }\end{array}$ \\
\hline Catch distribution strategy & $\begin{array}{l}\text { Uniformly distributed across } \\
\text { Management areas IV and V }\end{array}$ & $\begin{array}{l}\text { Distributed into sub-areas according to } \\
\text { spatial information on an annual scale }\end{array}$ & $\begin{array}{l}\text { Uniformly distributed within } \\
\text { Management areas IV and V }\end{array}$ \\
\hline Population dynamics model & $\begin{array}{l}\text { Mixing with density dependence acting } \\
\text { on the breeding areas }\end{array}$ & $\begin{array}{l}\text { Mixing with density dependence acting } \\
\text { on the breeding areas }\end{array}$ & $\begin{array}{l}\text { Mixing with density dependence } \\
\text { acting on the feeding areas }\end{array}$ \\
\hline Carrying capacity $(K)$ & Initial breeding stock number & Initial breeding stock number & Initial breeding stock number \\
\hline
\end{tabular}

The 'True' and 'Estimated' parameters ' $K$ ' (the number of whales at the start of the simulation) and ' $r$ ' (the intrinsic rate of increase) are also reported. Table 1 summarises the parameter values used in the simulations for the three scenarios.

Table 1

Parameter values for the simulations of the three test scenarios. 


\section{RESULTS}

\section{Base case}

There was little difference between the model fit and the underlying simulated population for the base case model. Hence it was possible to reliably gauge the sensitivity of estimates from the Johnston and Butterworth model to the mixing and catch allocation scenarios and changed density dependence (Scenarios 2 and 3). Table 2 details the results of the base case simulation and Fig. 4 shows the population trajectories for (a) stock D and (b) stock E.

\section{Non uniform mixing and catch allocation model}

A difference was found between the model fit and the underlying simulated population for only one of the simulation runs (shown in bold in Table 2); for stock D with a gamma mixing distribution and 120 sub areas (Fig. 5a). The population $K$ for the estimated population was higher, $\sim 32,500$ animals, than the 20,000 for the true population. Whilst both populations followed the same trajectory of decline and recovery, the estimated population recovered to a $K$ higher by 2050 . The estimated intrinsic growth rate $(r)$ for the estimated population was lower, 0.05 , as compared to 0.1 for the true population and the NMSE value was 0.0726 (Table 2).

There was little difference between the model fit and the underlying simulated population for all other simulations, an example of which is shown in Fig. 5b (stock E, gamma mixing and 120 sub-areas).

\section{Feeding area density dependence model}

There was a substantial difference between the model fit and the underlying simulated population for both stocks when density dependence was implemented on the feeding areas (Figs $6 \mathrm{a}$ and $6 \mathrm{~b}$, Table 2). For stock D, the initial population (i.e. $K$ ) for the estimated population was lower, $\sim 16,800$ animals, than the 25,000 for the true population. Population trajectories were most similar through a period of decline (1950-63) and recovery (1964-98), but where the estimated population reached initial $K(\sim 16,800$ animals $)$ by about 2020 , the true population, did not recover to an initial $K$ of 25,000 animals, and remained at a population size of $\sim 7,500$ from 2000-50 (Fig. 6a). The estimated intrinsic growth rate (r) was lower, $\sim 0.066$, than the 0.1 for the true population and the NMSE value was 0.415 (Table 2).

In contrast to stock $\mathrm{D}$, the initial population (i.e. $K$ ) for the estimated population of stock $\mathrm{E}$ was higher, $\sim 48,000$ animals, than the 30,000 for the true population. Population trajectories were most similar throughout the period 1950 2050 , but where the estimated population reached initial $K$ ( $\sim 8,000$ animals) by about 2020 , the true population reached the same $K$ as the estimated population (Fig. 7b). The estimated intrinsic growth rate $(r)$ for the estimated population was lower, $\sim 0.072$, than the 0.1 for the true population and the NMSE value was 0.1788 (Table 2).

\section{DISCUSSION}

In the base case scenario, the ability of the (Johnston and Butterworth, 2005a) model to estimate the population parameters from generated input data where the parameters values were unknown, was good. Therefore it was possible to gauge the sensitivity of the model to the mixing, catch allocation and density dependence scenarios with confidence. The Johnston and Butterworth (2005a) model was tested for alternate mixing and catch allocation on the feeding grounds on the basis of real data on whale movement and individual catch location, but found that the model was robust to more realistic specifications of these parameters in all but one simulation scenario. It would appear that whilst the combined effect of non-uniform mixing and non-uniform catch can produce a quite different underlying catch allocation than that specified in the Johnston and Butterworth (2005a) model, this introduces very little bias in the estimated population trajectory.

Alternative specifications for density dependence are especially important to consider in cases of models that allow

Table 2

Parameter estimates for 'True' and 'Estimated' populations and associated NMSE values for population trajectories for the three test scenarios.

\begin{tabular}{|c|c|c|c|c|c|c|c|c|c|c|}
\hline \multicolumn{11}{|l|}{ Scenario 1} \\
\hline Sub-areas & \multicolumn{10}{|c|}{ Uniform mixing and catch } \\
\hline Stock D & True K & Est K & True $\mathbf{r}$ & Est $\mathbf{r}$ & NMSE & & & & & \\
\hline 2 & 25,000 & 24,952 & 0.1 & 0.101 & 0.00012 & & & & & \\
\hline Stock E & True K & Est $\mathbf{K}$ & True $\mathbf{r}$ & Est $\mathbf{r}$ & NMSE & & & & & \\
\hline 2 & 30,000 & 30,069 & 0.1 & 0.099 & 0.00001 & & & & & \\
\hline \multicolumn{11}{|l|}{ Scenario 2} \\
\hline Sub-areas & \multicolumn{5}{|c|}{ Gamma mixing and catch } & \multicolumn{5}{|c|}{ Highend mixing and catch } \\
\hline Stock D & True K & Est K & True $\mathbf{r}$ & Est $\mathbf{r}$ & NMSE & True $\mathrm{K}$ & Est $\mathrm{K}$ & True $\mathbf{r}$ & Est $\mathbf{r}$ & NMSE \\
\hline 2 & 25,000 & 25,023 & 0.1 & 0.099 & 0.00016 & 25,000 & 24,984 & 0.1 & 0.101 & 0.00005 \\
\hline 12 & 25,000 & 25,002 & 0.1 & 0.099 & 0.0001 & 25,000 & 24,700 & 0.1 & 0.11 & 0.001 \\
\hline 24 & 25,000 & 26,374 & 0.1 & 0.084 & 0.0056 & 25,000 & 24,688 & 0.1 & 0.11 & 0.001 \\
\hline 60 & 25,000 & 24,996 & 0.1 & 0.1 & 0.009 & 25,000 & 24,659 & 0.1 & 0.112 & 0.002 \\
\hline 120 & 25,000 & 32,598 & 0.1 & 0.05 & 0.0726 & 25,000 & 24,661 & 0.1 & 0.11 & 0.002 \\
\hline Stock E & True K & Est $\mathrm{K}$ & True $\mathbf{r}$ & Est $r$ & NMSE & True K & Est $K$ & True $\mathbf{r}$ & Est $r$ & NMSE \\
\hline 2 & 30,000 & 30,480 & 0.1 & 0.099 & 0.00018 & 30,000 & 29,935 & 0.1 & 0.1 & 0.00002 \\
\hline 12 & 30,000 & 29,866 & 0.1 & 0.1 & 0.00007 & 30,000 & 29,300 & 0.1 & 0.99 & 0.0055 \\
\hline 24 & 30,000 & 30,003 & 0.1 & 0.099 & 0.00005 & 30,000 & 29,143 & 0.1 & 0.1 & 0.0074 \\
\hline 120 & 30,000 & 30,000 & 0.1 & 0.1 & 0.00003 & 30,000 & 29,008 & 0.1 & 0.1 & 0.009 \\
\hline \multicolumn{11}{|c|}{ Scenario 3} \\
\hline Sub-areas & \multicolumn{10}{|c|}{ Uniform mixing and catch } \\
\hline Stock D & True K & Est K & True $\mathbf{r}$ & Est $\mathbf{r}$ & NMSE & & & & & \\
\hline 2 & 25,000 & 16,825 & 0.1 & 0.066 & 0.41552 & & & & & \\
\hline Stock E & True K & Est $\mathrm{K}$ & True $\mathbf{r}$ & Est $\mathbf{r}$ & NMSE & & & & & \\
\hline 2 & 30,000 & 48,842 & 0.1 & 0.072 & 0.17888 & & & & & \\
\hline
\end{tabular}


(a)
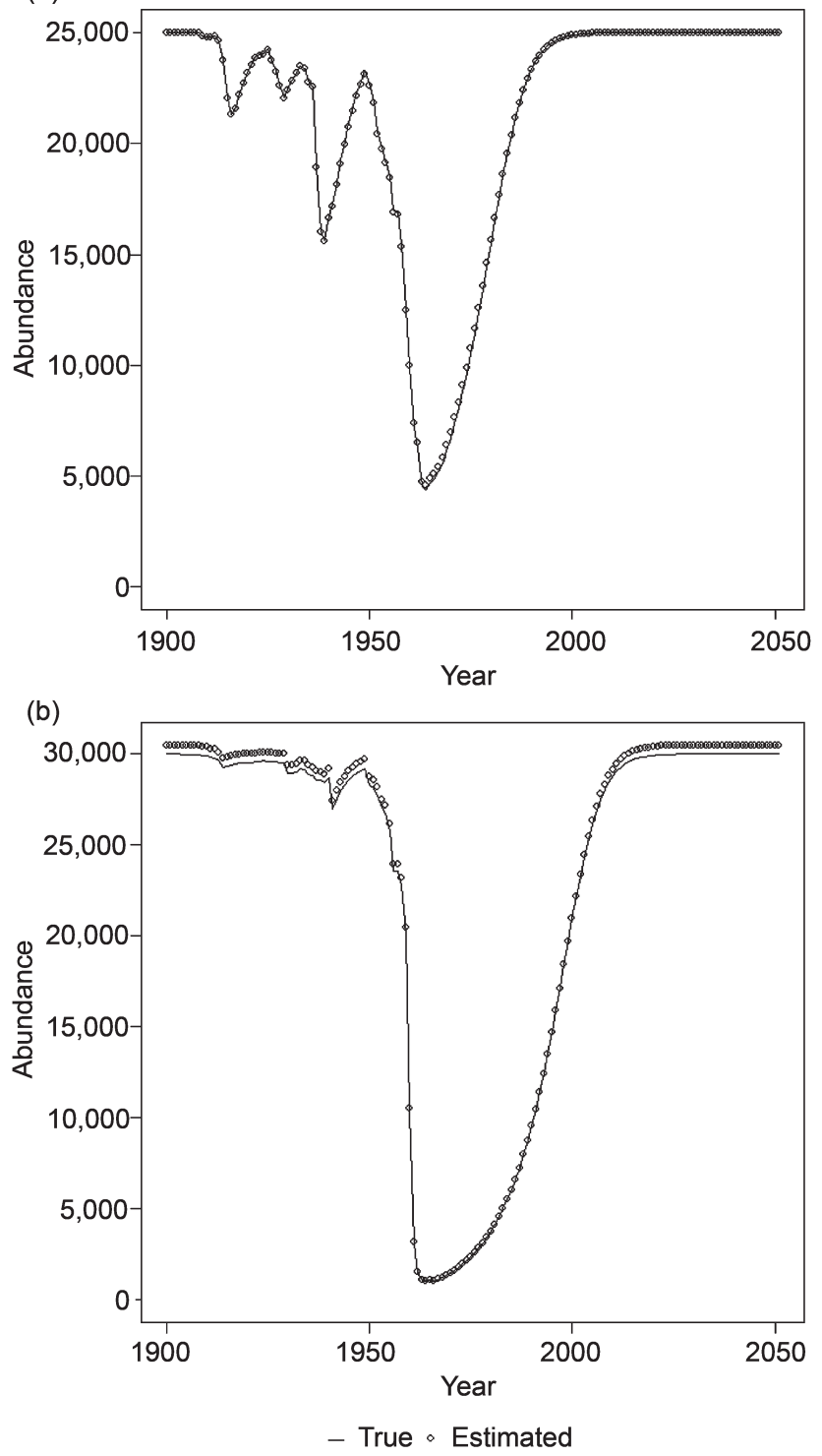

Fig. 4. Population trajectories 'True' versus 'Estimated' populations for (a) stock D and (b) stock E for the base case model. Note with initial populations $=(25,000,30,000$ respectively $)$ for both simulations.

stocks to mix, in that density dependence does not now act on breeding stocks independently. In this scenario, $K$ depends on the sum of the two population sizes and does not change between pre- and post-exploitation. Under the feeding area density dependent scenario, the Johnson and Butterworth model estimator performs poorly. In the case of stock $\mathrm{D}$, the model underestimates initial $K$ and overestimates recovery. In the case of stock E, initial $K$ is overestimated as equal to final $K$.

By the 1960 s both stock D and E were drastically reduced so their rate of increase at the cessation of whaling would have been close to $r$. However, stock D was reduced to lower numbers than stock E. Under the density dependence scenario and initial population abundance values used here, stock D cannot increase as fast as stock E and so the latter ends up accounting for the larger fraction of the total $K$ and stock D is forced to be smaller. This seems to clearly illustrate a case of changing carrying capacity for each stock, but there is no way the trajectories estimated from the Johnson and Butterworth model used can reflect this. The (a)

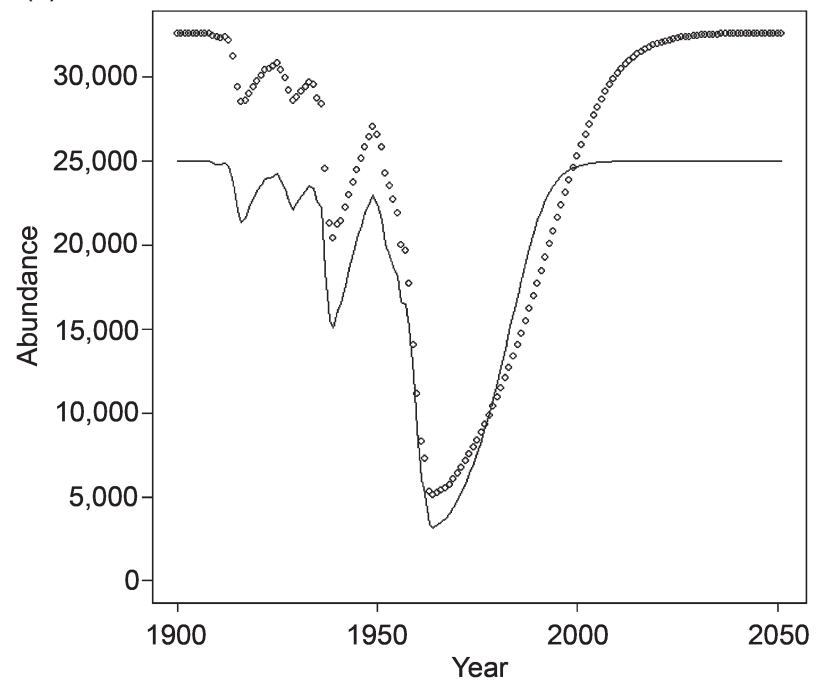

(b)

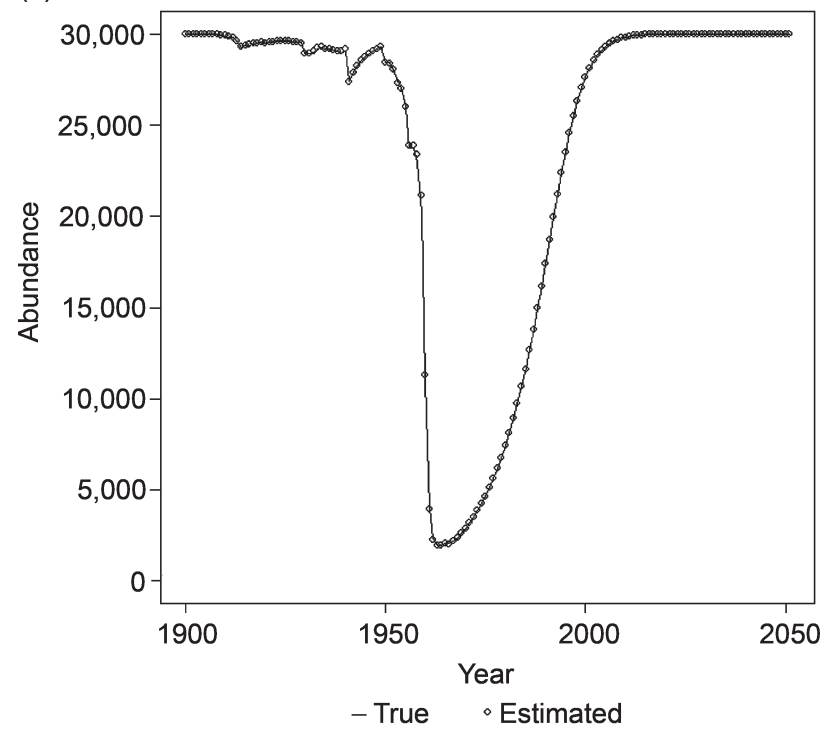

Fig. 5. Population trajectories 'True' versus 'Estimated' populations for (a) stock D with gamma mixing and 120 sub-areas and (b) stock E under gamma mixing and 120 sub-areas. Note with initial populations = $(25,000,30,000$ respectively) for both simulations.

simulations suggest that there may be differential recovery potential for two depleted stocks when density dependence operates on the feeding grounds and these two stocks mix on these feeding areas. Because the implementation of feeding area density dependence is intrinsically tied to the underlying process of mixing on the feeding area, there may be several plausible hypotheses for the process of mixing that have not been explored here.

Aside from the complexities of modelling feeding area density dependence when stocks are mixing, it is certainly plausible that after severe exploitation and subsequent recovery, whale populations (in the single stock case) may not return to their original level. For example, the North East Pacific stock of gray whales (Eschrichtius robustus), considered to be commercially extinct since the end of the $19^{\text {th }}$ century, is now believed to be approaching a level that may be higher than its historical $K$ (Moore et al., 2001; Rugh et al., 2005). In contrast, the Antarctic blue whale (Balaenoptera musculus intermedia) stock, also depleted to a small fraction of its original level, seems to have only 
(a)

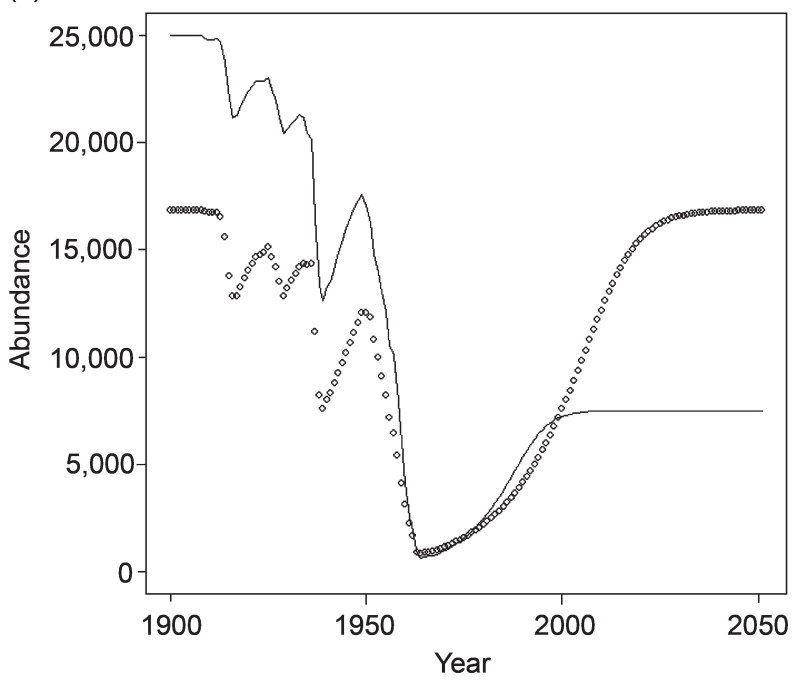

(b)

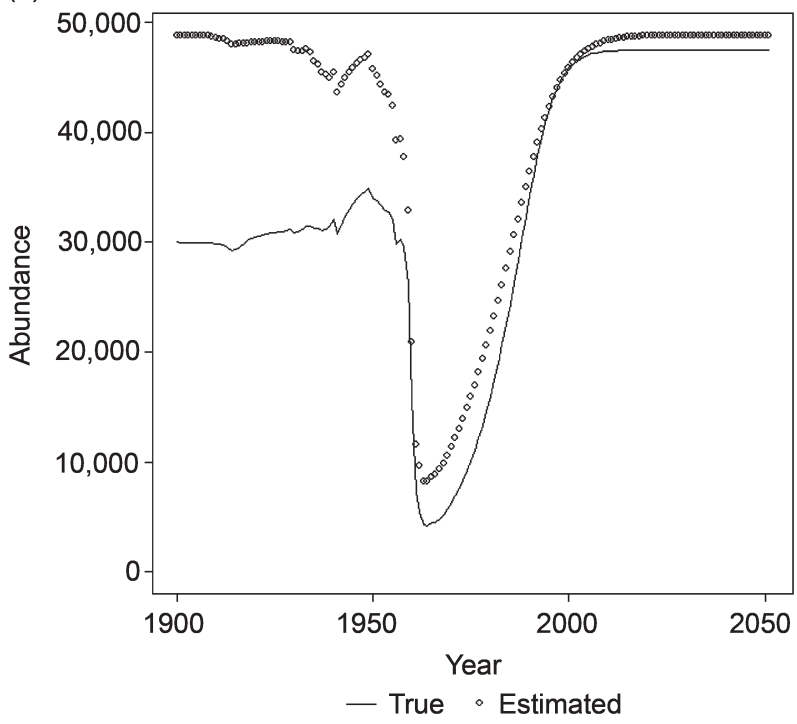

Fig. 6. Population trajectories 'True' versus 'Estimated' populations for (a) stock D with density dependence on the feeding areas and (b) stock E with density dependence on the feeding areas under uniform mixing and 2 sub-areas. Note with initial populations $=(25,000,30,000$ respectively $)$ for both simulations.

recovered to approximately $3 \%$ of its pre-exploitation level (Branch et al., 2007). In both these cases the notion that $K$ is fixed through time and never changes is open to debate.

The IWC has protected Southern Hemisphere humpback whale stocks since 1966, and blue whale stocks since 1965, but these species (and even different populations of the same species, i.e. humpback whales) have appeared to recover at very different rates. Baleen whale populations in the Southern Ocean are likely regulated by resource availability in their feeding areas rather than the breeding areas (unless they have very specific requirements). As just one component of a much larger predator guild, the recovery of whale populations will be influenced by the potential to interact trophically with other species.

In summary, the simulation approach taken here was conducted for illustrative purposes only, but served to demonstrate how alternative specifications for density dependence (e.g. on the feeding grounds rather than the breeding grounds) may be important to consider when stocks are mixing. Given that at least five of the seven putative stocks of humpback whales currently recognised in the Southern Hemisphere may mix on either feeding or breeding areas (or both), further exploration of multi-stock models is recommended.

\section{ACKNOWLEDGEMENTS}

Thanks to Mark Bravington for initial discussions on the paper. Thanks also to Phil Clapham and Paul Wade for advice on Russian catch data and Bayesian estimation respectively.

\section{REFERENCES}

Allison, C. 2006. Documentation of the creation of the Southern Hemisphere humpback catch series, February 2006, Cambridge, UK. Paper SC/A06/HW47 presented to the IWC Workshop on Comprehensive Assessment of Southern Hemisphere Humpback Whales, Hobart, Tasmania, 3-7 April 2006 (unpublished). 9pp. [Paper available from the Office of this Journal].

Branch, T.A., Stafford, K.M., Palacios, D.M., Allison, C., Bannister, J.L., Burton, C.L.K., Cabrera, E., Carlson, C.A., Galletti Vernazzani, B., Gill, P.C., Hucke-Gaete, R., Jenner, K.C.S., Jenner, M., Matsuoka, K., Mikhalev, Y., Miyashita, T., Morrice, M., Nishiwaki, S., Sturrock, V.J., Tormosov, D., Anderson, R.C., Baker, A.N., Best, P.B., Borsa, P., Brownell, R.L., Childerhouse, S., Findlay, K., Gerrodette, T., Ilangakoon, A.D., Joergensen, M., Kahn, D.K., Ljungblad, B., Maughan, B., McCauley, R.D., McKay, S., Norris, T.F., Oman Whale and Dolphin Research Group, Rankin, S., Samaran, F., Thiele, D., Van Waerebeek, K. and Warneke, R.M. 2007. Past and present distribution, densities and movements of blue whales in the Southern Hemisphere and northern Indian Ocean. Mammal Rev. 37(2): 116-75.

Chittleborough, R.G. 1959. Determination of age in the humpback whale, Megaptera nodosa (Bonnaterre). Aust. J. Mar. Freshwater Res. 10(2): 125-43. + 4 pls.

Chittleborough, R.G. 1965. Dynamics of two populations of the humpback whale, Megaptera novaeangliae (Borowski). Aust. J. Mar. Freshwater Res. 16(1): 33-128

Dawbin, W.H. 1966. The seasonal migratory cycle of humpback whales. pp.145-70. In: Norris, K.S. (eds). Whales, Dolphins, and Porpoises. University of California Press, Berkeley and Los Angeles. xv+789pp.

Findlay, K.P., Cunningham, C.L. and Butterworth, D.S. 2000. A first step towards a preliminary assessment of Southern Hemisphere humpback whales. Paper SC/52/IA5 presented to the IWC Scientific Committee, June 2000, in Adelaide, Australia (unpublished). 23pp. [Paper available from the Office of this Journal]

Friday, N., Punt, A.E. and Smith, T.D. 2001. A framework for the assessment of North Atlantic humpback whales, with illustrative examples. Paper SC/53/NAH16 presented to the IWC Scientific Committee, July 2001, London (unpublished). 12pp. [Paper available from the Office of this Journal].

International Whaling Commission. 1998. Report of the Scientific Committee. Annex G. Report of the sub-committee on Comprehensive Assessment of Southern Hemisphere humpback whales. Rep. int. Whal. Commn 48:170-82.

International Whaling Commission. 2001. Report of the Scientific Committee. Annex G. Report of the Sub-Committee on the Comprehensive Assessment of Whale Stocks - In-depth Assessments. $J$. Cetacean Res. Manage. (Suppl.) 3:177-208.

International Whaling Commission. 2002. Report of the Scientific Committee. Annex I. Report of the Working Group on Stock Definition. J. Cetacean Res. Manage. (Suppl.) 4:261-81.

International Whaling Commission. 2005. Report of the Scientific Committee. Annex H. Report of the sub-committee on other Southern Hemisphere whale stocks. J. Cetacean Res. Manage. (Suppl.) 7:235-44. International Whaling Commission. 2006. Report of the IWC Workshop on Future SOWER Cruises, Tokyo 1-4 October 2004. J. Cetacean Res. Manage. (Suppl.) 8:303-12.

International Whaling Commission. 2011. Report of the Workshop on the Comprehensive Assessment of Southern Hemisphere humpback whales, Hobart, Tasmania, 4-7 April 2006. J. Cetacean Res. Manage. (Special Issue 3): 1-50.

Johnston, S.J. and Butterworth, D.S. 2002. An assessment of the west and east Australian breeding stocks of Southern Hemisphere humpback whales using a model that allows for mixing in the feeding grounds. Paper SC/54/SH17 presented to the IWC Scientific Committee, April 2002, Shimonoseki, Japan (unpublished). 27pp. [Paper available from the Office of this Journal]. 
Johnston, S.J. and Butterworth, D.S. 2004. Updated age-aggregated production modelling assessments of the Southern Hemisphere humpback whale breeding stocks A and C. Paper SC/56/SH20 presented to the IWC Scientific Committee, July 2004, Sorrento, Italy (unpublished). 20pp. [Paper available from the Office of this Journal].

Johnston, S.J. and Butterworth, D.S. 2005a. Assessment of the west and east Australian breeding populations of Southern Hemisphere humpbacked whales using a model that allows for mixing on the feeding grounds and taking account of the most recent abundance estimates from JARPA. Paper JA/J05/JR19, presented to the JARPA Review Meeting, January 2005 (unpublished). [Paper available from the Office of this Journal].

Johnston, S.J. and Butterworth, D.S. 2005b. A Bayesian assessment of the west and east Australian breeding populations (stocks D and E) of Southern Hemisphere humpback whales. Paper SC/57/SH15 presented to the IWC Scientific Committee, June 2005, Ulsan, Korea (unpublished). 25pp. [Paper available from the Office of this Journal].
Johnston, S.J. and Butterworth, D.S. 2006. Updated assessments of various breeding populations of Southern Hemisphere humpback whales. Paper SC/A06/HW22 presented to the IWC Workshop on Comprehensive Assessment of Southern Hemisphere Humpback Whales, Hobart, Tasmania, 3-7 April 2006 (unpublished). 38pp. [Paper available from the Office of this Journal].

Moore, S., Urbán R, J., Perryman, W., Gulland, F., Perez-Cortes, H., RojasBracho, L. and Rowles, T. 2001. Are gray whales hitting ' $\mathrm{K}$ ' hard? Mar. Mammal Sci. 17(4): 954-58.

Rugh, D.J., Hobbs, R.C., Lerczak, J.A. and Breiwick, J.M. 2005. Estimates of abundance of the Eastern North Pacific stock of gray whales 1997 to 2002. J. Cetacean Res. Manage. 7(1): 1-12.

Zerbini, A.N. 2005. An updated Bayesian assessment of the Southern Hemisphere humpback whale Breeding Stock A. Paper SC/57/SH16 presented to the IWC Scientific Committee, June 2005, Ulsan, Korea (unpublished). 13pp. [Paper available from the Office of this Journal].

Appendix 1

SOUTHERN HEMISPHERE HUMPBACK WHALE CATCHES TO THE SOUTH OF $40^{\circ} \mathrm{S}$ APPORTIONED TO THE TWO FEEDING AREAS IV AND V

\begin{tabular}{|c|c|c|c|c|c|}
\hline Year & IWC IV (West) & IWC V (East) & Year & IWC IV (West) & IWC V (East) \\
\hline 1900 & 0 & 0 & 1941 & 0 & 0 \\
\hline 1901 & 0 & 0 & 1942 & 0 & 0 \\
\hline 1903 & 0 & 0 & 1944 & 0 & 0 \\
\hline 1904 & 0 & 0 & 1945 & 0 & 0 \\
\hline 1905 & 0 & 0 & 1946 & 0 & 0 \\
\hline 1906 & 0 & 0 & 1947 & 1 & 0 \\
\hline 1908 & 217 & 0 & 1949 & 878.4 & 813.6 \\
\hline 1909 & 118 & 0 & 1950 & $1,149.2$ & 136.8 \\
\hline 1910 & 83 & 0 & 1951 & $1,018.2$ & 472.8 \\
\hline 1911 & 0 & 0 & 1952 & 296.4 & 413.6 \\
\hline 1912 & 0 & 0 & 1953 & 261.8 & 11.2 \\
\hline 1913 & 0 & 0 & 1954 & 214 & 752 \\
\hline 1914 & 0 & 0 & 1955 & $1,639.6$ & 1898.4 \\
\hline 1915 & 0 & 0 & 1956 & 0 & 0 \\
\hline 1917 & 0 & 0 & 1958 & 4,092 & 1,652 \\
\hline 1918 & 0 & 0 & 1959 & $2,731.6$ & $9,890.4$ \\
\hline 1919 & 0 & 0 & 1960 & $2,497.2$ & $7,388.8$ \\
\hline 1920 & 0 & 0 & 1961 & 677.2 & $1,256.8$ \\
\hline 1921 & 0 & 0 & 1962 & $1,806.6$ & 378.4 \\
\hline 1922 & 0 & 0 & 1963 & 415.8 & 227.2 \\
\hline 1923 & 0 & 0 & 1964 & 106.2 & 68.8 \\
\hline 1924 & 0 & 0 & 1965 & 163.8 & 283.2 \\
\hline 1925 & 0 & 0 & 1966 & 133.2 & 44.8 \\
\hline 1926 & 16.4 & 65.6 & 1967 & 88.8 & 27.2 \\
\hline 1927 & 3.2 & 12.8 & 1968 & 1.2 & 0.8 \\
\hline 1928 & 14.4 & 13.6 & 1969 & 0 & 0 \\
\hline 1929 & 166 & 620 & 1970 & 0 & 0 \\
\hline 1930 & 74 & 188 & 1971 & 0 & 0 \\
\hline 1931 & 161 & 0 & 1972 & 0.4 & 1.6 \\
\hline 1932 & 82 & 0 & 1973 & 0 & 0 \\
\hline 1933 & 601 & 0 & 1974 & 0 & 0 \\
\hline 1937 & 842.4 & 25.6 & 1978 & 0 & 0 \\
\hline 1938 & 844.6 & 38.4 & 1979 & 0 & 0 \\
\hline 1939 & 0 & 0 & & & \\
\hline 1940 & 478.8 & $1,915.2$ & & & \\
\hline
\end{tabular}


Appendix 2

SIMULATION DATA AND MODEL SETTINGS

\begin{tabular}{lll}
\hline All test scenarios & Value for stock D & Value for stock E \\
Initial breeding stock numbers $^{1}$ & 20,000 & 30,000 \\
Intrinsic growth rate $^{\text {Time period }}{ }^{2}$ & 0.1 & 0.1 \\
Each simulation & 1900 to 2050 & 1900 to 2050 \\
Number of areas & Value & Management Areas IV and V \\
Number of stocks & Stocks D and E \\
Number of iterations & 100,000 \\
Catch - breeding ground & Naïve & Naïve (For Scenario 3, the finer scale spatial data is summed across the sub-areas within each management area \\
Catch - feeding area & to return it to the right format for input into the model) \\
& Size of simulated population in 1999 for each stock (each with coefficients of variation set to 0.00001) \\
Absolute (target) abundances & $5 \%$ of simulated population in the same years (as Table 1 of Johnston and Butterworth, 2005b) \\
Relative abundance - breeding ground & $70 \%$ of simulated population in the same years as JARPA data (Johnston and Butterworth, 2005b) \\
Relative abundance - feeding area & IWC/IDCR-SOWER estimates (Johnston and Butterworth, 2005b) \\
Comparison abundance &
\end{tabular}

${ }^{1}$ The initial breeding stock numbers were chosen so that all scenarios could be run without causing the catch to exceed the available stock in a given subarea/area for all years. Note that Scenarios 2 and 3 are particularly sensitive to this problem. ${ }^{2} 1900$ refers to austral summer season $1900 / 01$ and so on. 